\title{
A successful birth of severe secondary recurrent miscarriage case after a decline of phosphatidylserine-dependent anti-prothrombin antibody by intravenous immunoglobulin administration
}

\author{
Mika Kanaya ${ }^{1}$, Kunihiko Nagasawa², Tsuyoshi Baba², Shinichi Ishioka², Hideto Yamada ${ }^{3}$, \\ Toshiaki Endo $^{2 *}$, Tsuyoshi Saito ${ }^{2}$ \\ ${ }^{1}$ Mika Ladies Clinic, Sapporo, Japan \\ ${ }^{2}$ Department of Obstetrics and Gynecology, School of Medicine, Sapporo Medical University, Sapporo, Japan \\ ${ }^{3}$ Department of Obstetrics and Gynecology, School of Medicine, Kobe University, Kobe, Japan \\ Email: ${ }^{*}$ endot@sapmed.ac.jp, mikalady@dune.ocn.ne.jp, nkuni1107@yahoo.co.jp, tbaba@sapmed.ac.jp, ishioka000@yahoo.co.jp, \\ yhideto@med.kobe-u.ac.jp, tsaito@sapmed.ac.jp
}

Received 24 April 2012; revised 23 May 2012; accepted 31 May 2012

\begin{abstract}
A 33 years old woman was referred to our hospital since her sixth pregnancy had been revealed. In fact, at 19 years of age she had diagnosed as having systemic lupus erythematosus without organ failure. In addition, she had a past history of uncontrollable severe pregnancy-induced hypertension occurred during the second pregnancy, resulting in extremely premature delivery and following postpartum HELLP syndrome. It was so severe that we employed administration of dexamethasone and plasma exchange to ameliorate a life-threatening situation. In the course of her recovery it was revealed that she had been complicated with antiphospholipid antibodies, and at the same time we observed that phosphatidylserinedependent anti-prothrombin antibody IgG levels were declining as her condition was getting better. Thereafter, she became pregnant three times, but all pregnancies ended in miscarriage despite administration of prednisolone and anticoagulant therapy. Therefore, we realized that her recurrent miscarriages could not be prevented with generally acceptable therapies, so we tried intravenous immunoglobulin shortly after fetal heart beats were detected. In fact, her sixth pregnancy was going well, but we had to terminate it at the 35th week of gestation due to the onset of HELLP syndrome-like condition. However, she could achieve an almost intact pregnancy outcome without neonatal complications or persistently worsening postpartum HELLP syndrome-like condition. Considering the etiologic relation overlapping between systemic lupus erythematosus, antiphospholipid syndrome and recur-
\end{abstract}

*Corresponding author. rent miscarriage, intravenous immunoglobulin can be one of the treatment options for severe secondary recurrent miscarriage, although the evidence of the treatment is always certain. In addition, a decline of phosphatidylserine-dependent anti-prothrombin antibody IgG levels we observed in this case may represent its therapeutic immunomodulatory effects.

Keywords: Antiphospholipid Antibody; Antiphospholipid Syndrome; Intravenous Immunoglobulin; Recurrent Miscarriage; Systemic Lupus Erythematosus

\section{CASE REPORT}

A 33-year-old woman was refered for her sixth pregnancy, and a week later the gestational sac was appearing in her uterus. She had been followed due to systemic lupus erythematosus (SLE) since she was at 19 years of age, which seemed to cause her pregnancies result in one extremely premature delivery and four spontaneous abortions (Table 1).

Especially, while she was admitted due to uncontrollable severe pregnancy-induced hypertension (PIH) happened in the second pregnancy, detection of antiphospholipid antibodies (APA) and her past history was close to the condition of antiphospholipid syndrome (APS) (Table 2). At the same time, it was revealed that phosphatidylserine-dependent anti-prothrombin antibody (aPS/ PT) was relatively high. Eventually, four days after terminating her pregnancy at the $23^{\text {rd }}$ week of gestation, postpartum HELLP syndrome (class 1, according to the Mississippi Triple-class HELLP System [1]) occurred suddenly. Fortunately, she recovered by administration of 
Table 1. The outcome of her past pregnancies.

\begin{tabular}{|c|c|c|c|c|c|}
\hline age of the patient & gestational age & treatment procedure & the outcome & perivillous fibrin-deposition & chromosome test \\
\hline 23 у.о. & 8 weeks & none & $\mathrm{SA}^{*}$ & N.S. ${ }^{* *}$ & N.S. \\
\hline 27 у.о. & 23 weeks & none & premature delivery & & \\
\hline 29 y.o. & 8 weeks & aspirin + heparin + predonisolone & SA & + & normal \\
\hline 31 у.о. & 6 weeks & aspirin + heparin + predonisolone & SA & + & normal \\
\hline 31 у.о. & 8 weeks & aspirin + heparin + predonisolone & SA & + & normal \\
\hline
\end{tabular}

, , spontaneous abortion; ${ }^{* *}$, not specified.

Table 2. The result of anti-phospholipid antibody measurements during her clinical history.

\begin{tabular}{|c|c|c|c|}
\hline \multicolumn{4}{|c|}{ Time of measurements } \\
\hline & On admission during the $1^{\text {st }}$ pregnancy & $1^{\text {st }}$ trimester of the $6^{\text {th }}$ pregnancy & $2^{\text {nd }}$ trimester of the $6^{\text {th }}$ pregnancy \\
\hline aPS/PT (ELISA) & $16.2 \mathrm{U} / \mathrm{ml}$ & $4.1 \mathrm{U} / \mathrm{ml}$ & $12.0 \mathrm{U} / \mathrm{ml}$ \\
\hline $\mathrm{LAC}^{* *}(\mathrm{dRVVT})$ & 1.0 index & 1.0 index & 1.2 index \\
\hline$\beta 2 \mathrm{GPI} \mathrm{aCL}^{* * *}$ (ELISA) & $4.1 \mathrm{U} / \mathrm{ml}$ & $4.0 \mathrm{U} / \mathrm{ml}$ & $4.1 \mathrm{U} / \mathrm{ml}$ \\
\hline
\end{tabular}

, phosphatidylserine-dependent anti-prothrombin antibody; ${ }^{* *}$, lupus anti-coagulant, normal $\leq 1.3$ index; ${ }^{* * *}, \beta 2$-glycoprotein I-dependent anti-cardiolipin antibody, normal $\leq 3.5 \mathrm{U} / \mathrm{ml}$.

dexamethasone and plasma exchange with a decline of the aPS/PT IgG levels [2]. However, all of her following three pregnancies ended in spontaneous abortion despite administration of prednisolone and anticoagulant therapy (prednisolone $10 \mathrm{mg}$ per day, aspirin $81 \mathrm{mg}$ per day, and subcutaneously injected unfractionated heparin 10,000 IU per day). The findings of all pathologic specimens were perivillous fibrin deposition, and chromosomal tests of them were normal. Therefore, we speculated that she had some immunological disruption indirectly due to SLE but probably directly due to antiphospholipid antibody was contributing to these severe secondary recurrent miscarriages.

From this point of view, we decided to try intravenous immunoglobulin (IVIg) for prevention of recurrent miscarriage. As following the previous report [3], A total of $100 \mathrm{~g}$ of immunoglobulin ( $20 \mathrm{~g}$ per day for five consecutive days) was administered soon after the fetal heart beat was observed, and intravenous infusion of 15,000 IU of unfractionated heparin per day (minimum dose for achieving about 1.5 times longer APTT than normal) was also started concurrently (Figure 1).

After six-week in-patient treatment, she was discharged and regularly followed taking prednisolone and anticoagulant therapy (prednisolone $10 \mathrm{mg}$ per day, aspirin $81 \mathrm{mg}$ per day, and subcutaneously injected unfractionated heparin 10,000 IU per day) with maintaining APTT about 1.5 times longer than normal. The levels of aPS/PT which were $16 \mathrm{U} / \mathrm{ml}$ before IVIg administration showed $12 \mathrm{U} / \mathrm{ml}$ at the $24^{\text {th }}$ week of gestation (Table 2).
At the $35^{\text {th }}$ week of gestation, she was admitted again as blood test indicated slight liver dysfunction and thrombocytopenia. Hence, we speculated that these results might reflect the onset of HELLP syndrome (class 3, according to the Mississippi Triple-class HELLP System [1]) and decided to undertake a Cesarean section (Apgar score was 8 at 1 minute and 9 at 5 minutes, and the weight was $2406 \mathrm{~g}$ ). Intravenous infusion of 15,000 IU of unfractionated heparin per day was started from the $4^{\text {th }}$ postpartum day, because D-dimer elevated to $27.0 \mu \mathrm{g} / \mathrm{ml}$, which was considerably high even though the period soon after a Cesarean section was taken into consideration [4]. Fortunately, it normalized gradually with- out the onset of postpartum HELLP syndrome, and she was discharged on the $15^{\text {th }}$ postpartum day. Thereafter, she resumed administration of prednisolone and anticoagulant therapy (oral administration of low-dose aspirin only), and now she is followed without any complication related to SLE or APS.

\section{DISCUSSION}

APS is a new disease concept that was first advocated by Hughes in 1983, and pregnancy morbidity is one of its clinical characteristics [5]. In the Sapporo Criteria [6-8], which is the classification criteria for definite APS, past histories such as onset of symptoms relating to $\mathrm{PIH}$ and recurrent miscarriage are important clinical findings for diagnosing APS. It is also necessary to prove the existence of APA, especially lupus anticoagulant (LAC) or 2 -glycoprotein I-dependent anticardiolipin antibody $(\beta 2 \mathrm{GPI}$ 


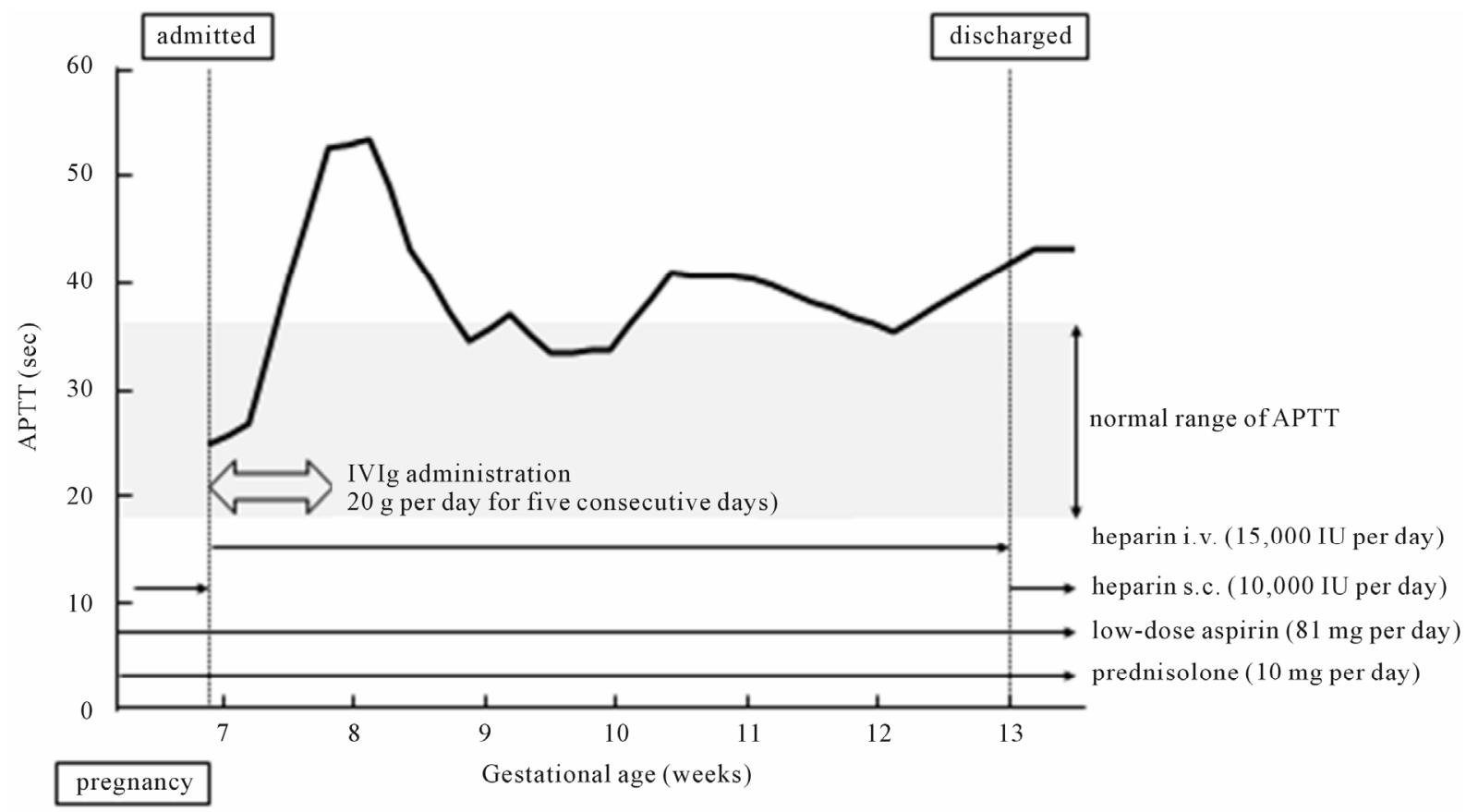

Figure 1. Clinical course in admission during her sixth pregnancy is shown. We tried IVIg for five consecutive days immediately after admission. Administration of prednisolone and anticoagulant therapy were employed concurrently. APTT, activated partial thromboplastin time; IVIg, intravenous immunoglobulin; i.v., intravenous injection; s.c., subcutaneous injection.

$\mathrm{aCL}$ ), which are included in the laboratory findings of the Sapporo Criteria. Recently, a part of LAC is thought to be antibodies against prothrombin. They comprise antibody directed against prothrombin alone coated on gamma-irradiated or activated polyvinylchloride ELISA plates (aPT-A: anti-prothrombin alone) and aPS/PT, which is antibody to the calcium-dependent phosphatidylserineprothrombin complex. Currently it is unclear what meaning measurement of aPT-A has, but it is thought that aPS/PT has a stronger correlation with clinical manifestations of APS. aPS/PT is also strongly correlated with thrombosis due to APS, and combined measurement of aPS/PT and $\beta 2 \mathrm{GPI}$ aCL provides high sensitivity and specificity for detecting APS $[9,10]$.

APS patients generally undergo acute phase thrombolytic therapy when necessary and anticoagulant therapy for preventing recurrent thrombosis [11]. Since the use of warfarin during pregnancy is contraindicated because of its teratogenicity, administration of low-dose aspirin and heparin are recommended, and their effectiveness for reducing pregnancy morbidity is evident [12].

SLE is an autoimmune disorder that affects various systemic organs and has a high prevalence rate in women of reproductive age $[13,14]$. Women with SLE tend to suffer from recurrent miscarriages because of the high complication rate with APS [13-15], and the American College of Rheumatology Revised Criteria for the Classification of Systemic Lupus Erythematosus includes a positive finding of antiphospholipid antibodies [16]. The main course of treatment for SLE is immunosuppressive therapy $[13,17]$. Clinically, steroids are administered according to the degree of SLE, and in case of complication with APS it is recommended that anticoagulant therapy also be done concurrently [18-20].

The therapeutic effectiveness of IVIg has been proved for some autoimmune disorders such as ITP [21], and now it is expected to be employed for many other autoimmune disorders, including SLE $[22,23]$. One metaanalysis of eight studies involving 442 women showed that IVIg increased the rates of live birth in secondary recurrent miscarriage [24], and Yamada et al. also reported that they achieved increasing live birth rates when using it to treat idiopathic recurrent miscarriage $[3,25]$.

At the $35^{\text {th }}$ week of gestation, we had to terminate her pregnancy before the onset of HELLP syndrome, but her pregnancy outcome was excellent without neonatal complications. IVIg has some mechanisms involved in various beneficial effects in different diseases $[21,26]$. Therefore it is very likely that some of them showed up and consequently led to a good pregnancy outcome. And a decline of the aPS/PT IgG levels after IVIg administration may indicate one of the therapeutic immunomodulatory effects.

It is the fact that this first tried IVIg made her pregnancy course much better than the other five past ones. Although this patient became pregnant three times after being diagnosed with APS, all of the pregnancies ended 
in spontaneous abortion despite administration of prednisolone and anticoagulant therapy (oral administration of low-dose aspirin and subcutaneously injected unfractionated heparin), so we expected that it must be very difficult how we should treat her at the next pregnancy. However, when postpartum HELLP syndrome occurred during her second pregnancy, we hypothesized that aPS/PT was one of the key agents related to its onset, and reducing the aPS/PT levels by administration of dexamethasone and plasma exchange resulted in successful treatment [2]. Considering such reported hypotheses as the strong correlation of aPS/PT with thrombosis $[9,10]$ and the onset of HELLP syndrome [2], we speculated that her severe secondary recurrent miscarriage may have been attributed to the increase of the aPS/PT IgG levels. So, this time we tried IVIg expecting to optimize it due to therapeutic immunomodulatory effects. Actually we could succeed in providing her with a good pregnancy outcome which had never been achieved.

It is possible that predonisolone and/or pregnancy per se may have provided optimization of the aPS/PT IgG levels, and negative LAC or maintaining APTT longer may have been attributed to a good pregnancy outcome. But if it had been true, we could have prevent her from encountering three spontaneous abortions by conventional therapy (i.e. administration of prednisolone and anticoagulant therapy) regardless of persistent high aPS/ PT IgG levels, but we failed miserably. But once we employed IVIg this time, in contrast the aPS/PT IgG levels were declining and we could achieve an excellent pregnancy outcome. This fact may indicate a significant relationship between a decline of the aPS/PT IgG levels and immunomodulatory effects of IVIg.

IVIg should not be employed for all cases of recurrent miscarriage because of its costs and benefits. However, one meta-analysis showed that IVIg increased the rates of live birth in secondary recurrent miscarriage [24], as it did for our patient. We found that the immunomodulatory effects of IVIg would improve her pregnancy course. It is unclear how the mechanisms had been working because the relation between aPS/PT and recurrent miscarriage has not been elucidated entirely, but the fact that the aPS/PT IgG levels declined after IVIg administration should be noted.

\section{CONCLUSION}

This time we tried IVIg for severe secondary recurrent miscarriage and achieved a good pregnancy outcome. We speculated that IVIg administration possibly improved her pregnancy outcome by decreasing aPS/PT IgG level, which is thought to be strongly related to thrombosis caused by APS. However, to reach a definitive conclusion it is necessary to collect more clinical and immu- nological evidence on the relation between aPS/PT and recurrent miscarriage.

\section{REFERENCES}

[1] Haram, K., Svendsen, E. and Abildgaard, U. (2009) The HELLP syndrome: Clinical issues and management. A review. BMC Pregnancy Childbirth, 9, 8. doi:10.1186/1471-2393-9-8

[2] Yamamoto, M., Nojima, M., Ohara, M., Suzuk, C., Naishiro, Y., Itoh, Y., Yamamoto, H., Takahashi, H., Kitajima, Y., Endo, T. and Imai, K. (2004) A case of systemic lupus erythematosus with postpartum hemolysis, elevated liver enzymes, and low platelet count (HELLP) syndrome and concomitant high phosphatidylserine-dependent antiprothrombin antibody levels. Modern Rheumatology, 14, 402-405. doi:10.1007/s10165-004-0331-4

[3] Yamada, H., Kishida, T., Kobayashi, N., Kato, E.H., Hoshi, N. and Fujimoto, S. (1998) Massive immunoglobulin treatment in women with four or more recurrent spontaneous primary abortions of unexplained aetiology. $\mathrm{Hu}$ man Reproduction, 13, 2620-2623.

[4] Epiney, M., Boehlen, F., Boulvain, M., Reber, G., Antonelli, E., Morales, M., Irion, O. and De Moerioose, P. (2005) D-dimer levels during delivery and the postpartum. Journal of Thrombosis and Haemostasis, 3, 268-271. doi:10.1111/j.1538-7836.2004.01108.x

[5] Hughes, G.R. (1983) Thrombosis, abortion, cerebral disease, and the lupus anticoagulant. British Medical Journal, 287, 1088-1089. doi:10.1136/bmj.287.6399.1088

[6] Wilson, W.A., Gharavi, A.E., Koike, T., Lockshin, M.D., Branch, D.W., Piette, J.C., Brey, R., Derksen, R., Harris, E.N., Hughes, G.R., Triplett, D.A. and Khamashta, M.A. (1999) International consensus statement on preliminary classification criteria for definite antiphospholipid syndrome: Report of an international workshop. Arthritis \& Rheumatism, 42, 1309-1311.

doi:10.1002/1529-0131(199907)42:7<1309::AID-ANR1 $>3.0 . \mathrm{CO} ; 2-\mathrm{F}$

[7] Lockshin, M.D., Sammaritano, L.R. and Schwartzman, S. (2000) Validation of the Sapporo criteria for antiphospholipid syndrome. Arthritis \& Rheumatism, 43, 440-443. doi:10.1002/1529-0131(200002)43:2<440::AID-ANR26 $>3.0 . \mathrm{CO} ; 2-\mathrm{N}$

[8] Miyakis, S., Lockshin, M.D., Atsumi, T., Branch, D.W., Brey, R.L., Cervera, R., Derkesen, R.H., Groot, P.G., Koike, T., Meroni, P.L., Reber, G., Shoenfeld, Y., Tincani, A., Vlachoyyiannopoulos, P.G. and Krilis, S.A. (2006) International consensus statement on an update of the classification criteria for definite antiphospholipid syndrome (APS). Journal of Thrombosis and Haemostasis, 4, 295306. doi:10.1111/j.1538-7836.2006.01753.x

[9] Oku, K., Atsumi, T., Amengual, O. and Koike, T. (2008) Antiprothrombin antibody testing: Detection and clinical utility. Seminars in Thrombosis and Hemostasis, 34, 335339. doi: $10.1055 / \mathrm{s}-0028-1085475$

[10] Amengual, O., Atsumi, T. and Koike, T. (2003) Specificities, properties, and clinical significance of antiprothrom- 
bin antibodies. Arthritis \& Rheumatism, 48, 886-895. doi:10.1002/art.10831

[11] Lim, W., Crowther, M.A. and Eikelboom, J.W. (2006) Management of antiphospholipid antibody syndrome: A systematic review. The Journal of American Medical Association, 295, 1050-1057. doi:10.1001/jama.295.9.1050

[12] Ruiz, I.G. and Khamashta, M.A. (2005) Management of thrombosis in antiphospholipid syndrome and systemic lupus erythematosus in pregnancy. Annals of the New York Academy of Sciences, 1051, 606-612. doi:10.1196/annals.1361.105

[13] D'Cruz, D.P., Khamashta, M.A. and Hughes, G.R. (2007) Systemic lupus erythematosus. Lancet, 369, 587-596. doi:10.1016/S0140-6736(07)60279-7

[14] Ruiz, I.G., Khamashta, M.A., Castellino, G. and Hughes, G.R. (2001) Systemic lupus erythematosus. Lancet, 357, 1027-1032. doi:10.1016/S0140-6736(00)04239-2

[15] McClain, M.T., Arbuckle, M.R., Heinlen, L.D., Dennis, G.J., Roebuck, J., Rubertone, M.V., Harley, J.B. and James, J.A. (2004) The prevalence, onset, and clinical significance of antiphospholipid antibodies prior to diagnosis of systemic lupus erythematosus. Arthritis \& Rheumatism, 50, 1226-1232. doi:10.1002/art.20120

[16] Hochberg, M.C. (1997) Updating the American College of Rheumatology revised criteria for the classification of systemic lupus erythematosus. Arthritis \& Rheumatism, 40, 1725. doi:10.1002/art.1780400928

[17] Gourley, M.F., Austin, H.A. II, Scott, D., Yarboro, C.H., Vaughan, E.M., Muir, J., Boumpas, D.T., Klippel, J.H., Balow, J.E. and Steinberg, A.D. (1996) Methylprednisolone and cyclophosphamide, alone or in combination, in patients with lupus nephritis. A randomized, controlled trial. Annals of Internal Medicine, 125, 549-557.

[18] Khamashta, M.A., Cuadrado, M.J., Mujic, F., Taub, N.A., Hunt, B.J. and Hughes, G.R. (1995) The management of thrombosis in the antiphospholipid-antibody syndrome. The New England Journal of Medicine, 332, 993-997. doi:10.1056/NEJM199504133321504

[19] Crowther, M.A., Ginsberg, J.S., Julian, J., Denburg, J., Hirsh, J., Douketis, J., Laskin, C., Fortin, P., Anderson, D., Kearon, C., Clarke, A., Geerts, W., Forgie, M., Green, D., Costantini, L., Yacura, W., Wilson, S., Gent, M. and Kovacs, M.J. (2003) A comparison of two intensities of warfarin for the prevention of recurrent thrombosis in pa- tients with the antiphospholipid antibody syndrome. The New England Journal of Medicine, 349, 1133-1138. doi:10.1056/NEJMoa035241

[20] Finazzi, G., Marchioli, R., Brancaccio, V., Schinco, P., Wisloff, F., Musial, J., Baudo, F., Berrettini, M., Testa, S., D’Angelo, A., Tognoni, G. and Barbui, T. (2005). A randomized clinical trial of high-intensity warfarin vs conventional antithrombotic therapy for the prevention of recurrent thrombosis in patients with the antiphospholipid syndrome (WAPS). Journal of Thrombosis and Haemostasis, 3, 848-853. doi:10.1111/j.1538-7836.2005.01340.x

[21] Kazatchkine, M.D. and Kaveri, S.V. (2001) Immunomodulation of autoimmune and inflammatory diseases with intravenous immune globulin. The New England Journal of Medicine, 345, 747-755. doi:10.1056/NEJMra993360

[22] Schroeder, J.O., Zeuner, R.A., Euler, H.H. and Loffler, H. (1996) High dose intravenous immunoglobulins in systemic lupus erythematosus: Clinical and serological results of a pilot study. Journal of Rheumatology, 23, 7175.

[23] Levy, Y., Sherer, Y., Ahmed, A., Langevitz, P., George, J., Fabbrizzi, F., Terryberry, J., Meissner, M., Lorber, M., Peter, J.B. and Shoenfeld Y. (1999) A study of 20 SLE patients with intravenous immunoglobulin-Clinical and serologic response. Lupus, 8, 705-712. doi:10.1191/096120399678841007

[24] Hutton, B., Sharma, R., Fergusson, D., Tinmouth, A., Hebert, P., Jamieson, J. and Walker, M. (2007) Use of intravenous immunoglobulin for treatment of recurrent miscarriage: A systematic review. An International Journal of Obstetrics \& Gynaecology, 114, 134-142.

[25] Morikawa, M., Yamada, H., Kato, E.H., Shimada, S., Kishi, T., Yamada, T., Kobashi, G. and Fujimoto, S. (2001) Massive intravenous immunoglobulin treatment in women with four or more recurrent spontaneous abortions of unexplained etiology: Down-regulation of NK cell activity and subsets. American Journal of Reproductive Immunology, 46, 399-404. doi:10.1034/j.1600-0897.2001.d01-31.x

[26] Samuelsson, A., Towers, T.L. and Ravetch, J.V. (2001) Anti-inflammatory activity of IVIG mediated through the inhibitory Fc receptor. Science, 291, 484-486. doi:10.1126/science.291.5503.484 